\title{
Excess risk of kidney disease in a population living near industrial plants
}

\author{
S Hodgson, M J Nieuwenhuijsen, A Hansell, S Shepperd, T Flute, B Staples, P Elliott, L Jarup
}

Occup Environ Med 2004;61:717-719. doi: 10.1136/oem.2003.010629

Runcorn has been a site of chemical industry activity for over a century, where tons of toxic chemicals are released annually to air and water. Excess kidney disease mortality (nephritis, nephrotic syndrome, and nephrosis) was found in the population living within $2 \mathrm{~km}$ of the industrial plants (standardised mortality ratio (SMR) in males 131 (95\% Cl 90 to 185$)$ and females 161 (95\% Cl 118 to 214$)$ ) compared to a reference population (northwest England)). Risk of hospital admissions for kidney disease in Halton (comprising the towns of Runcorn and Widnes) was higher than in the less industrial, nearby town of Warrington. The standardised admission ratio (SAR) in Halton was $115(95 \% \mathrm{Cl} 107$ to 124) for males and $126(95 \% \mathrm{Cl} 117$ to 137$)$ for females; and in Warrington 91 (95\% Cl 85 to 97) for males and 84 (95\% Cl 78 to 91 ) for females compared to the Warrington and Halton area as a whole. The excess risk of kidney disease in the Runcorn area requires further investigation.

A commentary published in The Lancet in January 1880 describes how the town of Runcorn is "exposed to the irritating vapour cast off so freely by the large chemical works in its vicinity". ${ }^{1}$ Today, over a century since this report, Runcorn is still exposed to many toxic chemicals released from over a dozen industrial plants in the area. Emissions data from the UK Environment Agency Pollution Inventory ${ }^{2}$ show that substantial amounts of nephrotoxic chemicals, including 125 tons lead, 4 tons mercury, and over a ton of arsenic and chromium were released to air from 16 plants (located on eight sites; fig 1) in the Runcorn area between 1998 and 2000. All these substances have toxic effects on a range of human organs, including the kidneys. ${ }^{3}$ Three sites are responsible for the majority of nephrotoxic emissions, with mercury being the major nephrotoxin released in Runcorn. It should be noted that current emissions are much lower than those experienced in the past, as shown by metals in sediment from the Mersey estuary over the past century. ${ }^{4}$

In collaboration with the former North Cheshire Health Authority (now Warrington and Halton Primary Care Trusts), we undertook preliminary investigations into the health of the population living in the vicinity of these industrial plants in Runcorn. The aim of this study was to determine if there was an excess risk of kidney mortality and morbidity in people living near these industrial plants. Kidney morbidity and mortality was the main concern because of the nephrotoxicants known to be released in the area, and because of the findings of previous investigations.

\section{METHODS}

Mortality was investigated using routinely collected data supplied by the Office for National Statistics (ONS) and analysed using the SAHSU Rapid Inquiry Facility (RIF). ${ }^{6}$
Distance from the industrial plants was used as a proxy for exposure.

Standardised mortality ratios (SMR) adjusted for socioeconomic deprivation ${ }^{7}$ were calculated for deaths from nephritis, nephrotic syndrome, and nephrosis (ICD9 580589) over the years 1981-99 for populations living in enumeration districts with population weighted centroids falling within $0-2 \mathrm{~km}$ and $2.01-7.5 \mathrm{~km}$ of the installations, using the postcode of residence mapped onto those enumeration districts to locate the $\operatorname{cases}^{6}$ (fig 1). Expected figures were derived from the northwest region population. Enumeration districts are the smallest unit of the national census and can be aggregated to electoral ward boundaries.

Morbidity was assessed by North Cheshire Health Authority (NCHA), who investigated kidney disease at electoral ward level using routinely collected local hospital admissions data (Patient Information System, Central Patient Activity Database, and Commissioning Minimum Datasets). These data were available from 1990 to 1999, and were used to calculate district age standardised admission ratios (SAR) for non-malignant renal disease as well as kidney cancer (ICD9 580-583 (except 581.8, 582.8, and 583.8), 585-587, 189.0; ICD10 N00-N06, N10, N11.8, N11.9, N15.8, N18, N19, N26, C64) using the population of Warrington and Halton as a reference. Where several hospital episodes involved the same person, that person was counted only once.

Ethical approval for use of routine data has been granted to SAHSU by St Mary's Local Research and Ethics Committee.

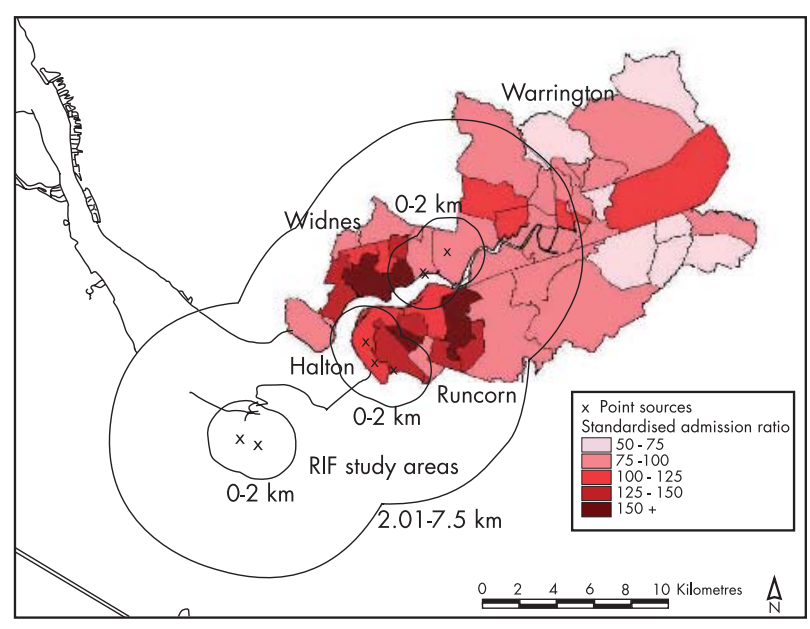

Figure 1 Standardised admission ratios for kidney disease in the North Cheshire area (shaded areas); 0-2 and 2.01-7.5 km Rapid Inquiry Facility (RIF) exposure areas used in the mortality analysis (circled areas) and location of point sources (16 sources on eight sites). 
Table 1 Relation between proximity to chemical installations and risk of mortality from nephritis, nephrotic syndrome, and nephrosis (ICD9 580-589)

\begin{tabular}{|c|c|c|c|c|c|c|c|c|c|c|}
\hline \multirow{2}{*}{$\begin{array}{l}\text { Distance from } \\
\text { point source }\end{array}$} & \multirow[b]{2}{*}{ Sex } & \multirow[b]{2}{*}{ Person-years } & \multicolumn{4}{|c|}{ Adjusted for age (sex) } & \multicolumn{4}{|c|}{ Adjusted for age (sex) deprivation } \\
\hline & & & Obs & Exp & SMR & $95 \% \mathrm{Cl}$ & Obs & Exp & SMR & $95 \% \mathrm{Cl}$ \\
\hline \multirow[t]{3}{*}{$0-2 \mathrm{~km}$} & Males & 390699 & 32 & 23.9 & 134 & 92 to 189 & 32 & 24.4 & 131 & 90 to 185 \\
\hline & Females & 406581 & 47 & 29.3 & 160 & 118 to 213 & 47 & 29.2 & 161 & 118 to 214 \\
\hline & Males and females & 797280 & 79 & 53.2 & 149 & 118 to 185 & 79 & 53.6 & 147 & 117 to 184 \\
\hline \multirow[t]{3}{*}{$2.01-7.5 \mathrm{~km}$} & Males & 2941656 & 166 & 152.0 & 109 & 94 to 127 & 166 & 154.4 & 108 & 92 to 125 \\
\hline & Females & 3041976 & 206 & 182.5 & 113 & 98 to 129 & 206 & 185.9 & 111 & 97 to 127 \\
\hline & Males and females & 5983632 & 372 & 334.5 & 111 & 100 to 123 & 372 & 340.3 & 109 & 99 to 121 \\
\hline
\end{tabular}

\section{RESULTS}

There were 451 deaths from nephritis, nephrotic syndrome, and nephrosis in the population living within $0-7.5 \mathrm{~km}$ from the industrial plants. There was excess SMR within $7.5 \mathrm{~km}$ which was higher at $0-2 \mathrm{~km}$ than $2.01-7.5 \mathrm{~km}$, although confidence intervals overlapped (table 1).

A similar pattern was seen for kidney morbidity (2804 individuals admitted to hospital) when mapped by electoral ward across North Cheshire (fig 1). When the ward data were pooled to town level there were excess risks of kidney morbidity in Runcorn and Widnes with SAR of 122 (95\% CI 110 to 136$)$ in males, 136 (95\% CI 122 to 151$)$ in females in Runcorn; and 108 (95\% CI 97 to 120) in males, and 117 (95\% CI 104 to 132) in females in Widnes, in contrast to Warrington (SAR of 91 (95\% CI 85 to 97) in males and 84 (95\% CI 78 to 91) in females), which has far fewer sources of pollution.

\section{DISCUSSION}

By using distance from point sources as a proxy for exposure to pollutants from industrial plants we have observed a significant excess of kidney mortality in people living nearest to several polluting sources after adjustment for socioeconomic deprivation. Similarly, kidney morbidity appears to be highest in the areas closest to the industrial plants. These trends may be associated with exposure to kidney toxicants, which have been emitted by these plants over the past century.

\section{Main messages}

- There is a significant excess of kidney disease and kidney disease mortality in people living near to several polluting sources in Runcorn.

- These excesses may be associated with exposure to kidney toxicants emitted by these plants over the past century.

- Morbidity and mortality ratios were more pronounced in females than males, suggesting that occupation in not a substantial confounder.

\section{Policy implications}

- Since there was an excess risk of kidney mortality and morbidity in areas with potential exposure to renal toxicants released from nearby industrial plants, further work is needed to investigate whether the excess risks are causally related to chemical pollution in the area.
Ecological analyses and disease mapping are relatively crude methods for establishing health risks associated with point source pollution, especially in this area where historical land contamination and industrial landfill sites may contribute to chemical exposure via pathways other than inhalation. However, we have observed a consistent pattern in kidney disease morbidity and mortality from two independent data sources.

Exposure will be affected by occupation (in this area the industrial plants provide a major source of employment) and diet. However, both morbidity and mortality ratios in females were more pronounced than in males (who are much more likely to be occupationally exposed), suggesting that occupation is not a substantial confounder.

\section{Conclusions}

We found an excess risk of kidney mortality and morbidity in areas with potential exposure to renal toxicants released from nearby industrial plants. Further work is planned (including more detailed exposure assessment, exploring different exposure pathways) to investigate whether the excess risks are causally related to chemical pollution in the area.

\section{ACKNOWLEDGEMENTS}

The Small Area Health Statistics Unit is funded by a grant from the Department of Health, Department of the Environment, Food and Rural Affairs, Environment Agency, Health and Safety Executive, Scottish Executive, Welsh Assembly Government, and Northern Ireland Department of Health, Social Services and Public Safety. We thank the Office for National Statistics (ONS) for provision of mortality data. The views expressed in this publication are those of the authors and not necessarily those of the funding departments, data providers, or of ONS.

\section{Authors' affiliations}

S Hodgson, A Hansell, S Shepperd, P Elliott, L Jarup, Small Area Health Statistics Unit (SAHSU), Imperial College London, UK

M J Nieuwenhuijsen, Dept Environmental Science and Technology, Imperial College London, UK

T Flute, Halton Primary Care Trust and Warrington Primary Care Trust, UK

B Staples, Formerly Consultant Environmental Health, North Cheshire Health Authority, UK

The authors would like to thank the Medical Research Council for PhD studentship support of S Hodgson.

The morbidity analysis was undertaken by the North Cheshire Health Surveillance Project. Funding was provided by local industry.

Correspondence to: Dr L Jarup, SAHSU, Department of Epidemiology and Public Health, Faculty of Medicine, St Mary's Campus, Imperial College London, Norfolk Place, London W2 1PG, UK; I.jarup@imperial. ac.uk

Accepted 28 November 2003 


\section{REFERENCES}

1 Anon. The sanitary state of Runcorn. Lancet 1880 Jan 24:142-3.

2 Environment Agency. http://216.31.193.171/asp/introduction.asp. 2002

3 WHO. Principles and methods for the assessment of nephrotoxicity associated with exposure to chemicals [119]. WHO, 1991.

4 The Environment Agency. The state of the environment in the north west of England. The Environment Agency, 1998.
5 Staples B, Howse M, Mason H, et al. Land contamination and urinary abnormalities: cause for concern? Occup Environ Med 2003;60:463-7.

6 Aylin P, Maheswaran R, Wakefield J, et al. A national facility for small area disease mapping and rapid initial assessment of apparent disease clusters around a point source: the UK Small Area Health Statistics Unit. J Public Health Med 1999;21:289-98.

7 Carstairs V, Morris R. Deprivation and health in Scotland. Health Bulletin 1990;48:162-75.

\section{Clinical Evidence-Call for contributors}

Clinical Evidence is a regularly updated evidence based journal available worldwide both as a paper version and on the internet. Clinical Evidence needs to recruit a number of new contributors. Contributors are health care professionals or epidemiologists with experience in evidence based medicine and the ability to write in a concise and structured way.

Currently, we are interested in finding contributors with an interest in the following clinical areas:

Altitude sickness; Autism; Basal cell carcinoma; Breast feeding; Carbon monoxide poisoning; Cervical cancer; Cystic fibrosis; Ectopic pregnancy; Grief/bereavement; Halitosis; Hodgkins disease; Infectious mononucleosis (glandular fever); Kidney stones; Malignant melanoma (metastatic); Mesothelioma; Myeloma; Ovarian cyst; Pancreatitis (acute); Pancreatitis (chronic); Polymyalgia rheumatica; Post-partum haemorrhage; Pulmonary embolism; Recurrent miscarriage; Repetitive strain injury; Scoliosis; Seasonal affective disorder; Squint; Systemic lupus erythematosus; Testicular cancer; Varicocele; Viral meningitis; Vitiligo However, we are always looking for others, so do not let this list discourage you.

\section{Being a contributor involves:}

- Appraising the results of literature searches (performed by our Information Specialists) to identify high quality evidence for inclusion in the journal.

- Writing to a highly structured template (about 2000-3000 words), using evidence from selected studies, within 6-8 weeks of receiving the literature search results.

- Working with Clinical Evidence Editors to ensure that the text meets rigorous epidemiological and style standards.

- Updating the text every eight months to incorporate new evidence.

- Expanding the topic to include new questions once every 12-18 months.

If you would like to become a contributor for Clinical Evidence or require more information about what this involves please send your contact details and a copy of your CV, clearly stating the clinical area you are interested in, to Claire Folkes (cfolkes@bmigroup.com).

\section{Call for peer reviewers}

Clinical Evidence also needs to recruit a number of new peer reviewers specifically with an interest in the clinical areas stated above, and also others related to general practice. Peer reviewers are health care professionals or epidemiologists with experience in evidence based medicine. As a peer reviewer you would be asked for your views on the clinical relevance, validity, and accessibility of specific topics within the journal, and their usefulness to the intended audience (international generalists and health care professionals, possibly with limited statistical knowledge). Topics are usually 2000-3000 words in length and we would ask you to review between 2-5 topics per year. The peer review process takes place throughout the year, and our turnaround time for each review is ideally 10-14 days.

If you are interested in becoming a peer reviewer for Clinical Evidence, please complete the peer review questionnaire at www.clinicalevidence.com or contact Claire Folkes(cfolkes@bmigroup.com). 